\title{
Nestin regulates proliferation, migration, invasion and stemness of lung adenocarcinoma
}

\author{
KOSUKE NARITA $^{1,2}$, YOKO MATSUDA ${ }^{1}$, MASAHIRO SEIKE $^{2}$, ZENYA NAITO $^{1}$, \\ AKIHIKO GEMMA $^{2}$ and TOSHIYUKI ISHIWATA ${ }^{1}$ \\ ${ }^{1}$ Departments of Pathology and Integrative Oncological Pathology, Nippon Medical School, Tokyo 113-8602; \\ ${ }^{2}$ Department of Pulmonary Medicine and Oncology, Graduate School of Medicine, \\ Nippon Medical School, Tokyo 113-8603, Japan
}

Received November 25, 2013; Accepted January 7, 2014

DOI: $10.3892 /$ ijo.2014.2278

\begin{abstract}
Lung cancer is the most common cancer and the most common cause of cancer-related death in the world. Nestin, a class VI intermediate filament, is known to be a cancer stem cell (CSC) marker as well as a neuroepithelial stem cell marker. High expression levels of nestin are reported in several types of cancers including lung, pancreatic and prostate cancers. Nestin is thought to regulate tumor cell proliferation, migration, invasion and CSC properties. Here, we confirmed nestin expression in non-small cell lung cancer (NSCLC): Immunohistochemical analysis in surgical specimens detected nestin protein expression in the cytoplasm of 20 of 48 adenocarcinoma (AD) cases (41.7\%) and 25 of 47 squamous cell carcinoma cases $(53.2 \%)$. Nestin immunoreactivity significantly correlated with not only tumor size and lymph node metastasis in NSCLC, but also poor survival in surgical patients with AD. High and moderate expression levels of nestin were confirmed in several lung AD cell lines including H1975 and PC-3. Nestin inhibition by shRNA decreased proliferation, migration, invasion and sphere formation in AD cells. Correspondingly, nestin upregulation by nestin gene transfection resulted in the opposite changes. Moreover, Akt inhibitor IV effectively decreased nestin expression via SRY-box containing protein 2 (Sox2) downregulation and overcame the enhanced sphere formation induced by nestin upregulation. Overall, our results show that nestin correlates with the aggressiveness and stemness of AD. Regulation of nestin via Akt/Sox 2 is, thus, a promising candidate for novel therapeutic approaches to eradicate CSCs in lung AD.
\end{abstract}

Correspondence to: Dr Toshiyuki Ishiwata, Departments of Pathology and Integrative Oncological Pathology, Nippon Medical School, 1-1-5 Sendagi, Bunkyo-ku, Tokyo 113-8602, Japan

E-mail: ishiwata@nms.ac.jp

Key words: nestin, lung cancer, Akt inhibitor IV, SRY-box containing protein 2 , cancer stem cell

\section{Introduction}

Lung cancer is the most common cancer and the most common cause of cancer-related death, representing $12.7 \%$ of all new cancers and causing $18.2 \%$ of total cancer deaths worldwide (1). At diagnosis, more than $50 \%$ of patients have distant metastases and $25 \%$ have lymph node metastases (2). Despite numerous therapeutic advances in lung cancer treatment $(3,4)$, the prognosis remains dismal. The 5-year survival rate is $16 \%$ for all stages of lung cancer, and is only $45 \%$ even when only considering cases with lung-localized cancer $(2,3)$. Histopathologically, lung cancer is classified into small cell lung cancer (SCLC) and non-small cell lung cancer (NSCLC), the latter including adenocarcinoma (AD), squamous cell carcinoma (SCC) and large cell carcinoma. AD is the most common histological subtype of NSCLC (5). Molecular-targeted therapies for $\mathrm{AD}$ have been introduced in clinical settings, including epidermal growth factor receptor (EGFR)-tyrosine kinase inhibitors (TKIs) and crizotinib, which is an oral TKI that targets the oncogenic fusion product comprising echinoderm microtubule-associated protein-like 4 (EML4) and anaplastic lymphoma kinase (ALK) $(4,6,7)$. However, acquired resistances against these molecular-targeting therapies are inevitable (8-10); therefore, new treatment strategies are needed to improve the prognosis of lung cancer patients.

Nestin is a class VI intermediate filament with a short $\mathrm{N}$-terminal extremity, which forms a heterodimer $(11,12)$. It is also known as a neuronal stem/progenitor cell marker (13). High nestin expression levels are observed in developing fetal tissues (14), as well as in various malignant tumors, including glioblastoma (15), malignant melanoma (16), and pancreatic $(17,18)$ and prostate $(19)$ cancers. Previous studies of these malignant tumors have shown that nestin expression correlates to worse prognosis, and that nestin inhibition suppresses tumor cell migration, invasion, metastasis and stemness (20). Nestin expression has been also reported in lung cancers, with high nestin expression reportedly correlated with poor prognosis (21-23), lymphovascular invasion $(21,24)$, and stemness $(25)$ in surgically treated NSCLC cases. Nestin inhibition also reportedly reduces cell growth and invasion in SCLC (26). However, the detailed roles and molecular regulatory mechanisms of nestin expression in lung cancers are not well understood. 
In the present study, we determine the expression patterns and roles of nestin in NSCLC. Our findings show that nestin downregulation induces anticancer effects, and that the Akt/SRY-box containing protein 2 (Sox2) signaling pathway regulates nestin expression in AD. These findings will enable us to develop the therapeutic strategies that target nestin in lung cancers.

\section{Materials and methods}

Materials. Materials purchased: mouse monoclonal anti-nestin antibody and recombinant human epidermal growth factor (EGF) from R\&D Systems, Inc. (Minneapolis, MN); Histofine Simple Stain MAX PO (M) and (R) kits from Nichirei (Tokyo, Japan); High Capacity cDNA Reverse Transcription Kit, TaqMan Fast Universal PCR master mix, and TaqMan Gene Expression Assays for nestin (Hs00707120_s1) and 18S rRNA (Hs99999901_s1), pre-designed siRNAs targeting human nestin (s21143: siRNA-A and s21141: siRNA-B), negative control siRNA (silencer select negative control no. 2: siControl), TaqMan Fast Cells-to-CT kit, Alexa 488-labeled donkey anti-mouse IgG antibody, Qubit Fluorometer Protein Assay Kit, and Geneticin from Life Technologies (Carlsbad, CA); TransIT-si-QUEST transfection reagent from Mirus Bio LLC (Madison, WI); pBAsi-hU6 Neo DNA vector and FastPure RNA Kit from Takara Bio, Inc. (Shiga, Japan); pAcGFP1-N1 from Clontech Laboratories (Mountain View, CA); FuGene HD transfection reagent from Promega Corporation (Madison, WI); Vectashield H-1200 containing 4',6-diamidino-2-phenylindole$2 \mathrm{HCl}$ (DAPI) from Vector Laboratories, Inc. (Burlingame, CA); WST-8 cell counting kit from Wako Pure Chemical Industries (Osaka, Japan); BioCoat Matrigel invasion chamber from BD Biosciences (Franklin Lakes, NJ); Diff-Quick staining kit from Sysmex International Reagents Co., Ltd. (Hyogo, Japan); recombinant human basic fibroblast growth factor (bFGF) from ReproCell, Inc. (Kanagawa, Japan); ultra-low attachment surface 24-well plate from Corning (Corning, NY); Akt inhibitor IV (no. 124011; CAS no. 681281-88-9), SB203580 (no. 559389; CAS no. 152121-47-6), and U0126 (no. 662005; CAS no. 109511-58-2), and rabbit polyclonal anti-Sox2 antibody from Merck KGaA (Darmstadt, Germany); Super Signal West Dura Extended Duration chemiluminescent substrates from Thermo Scientific (Waltham, MA); mouse monoclonal antiglyceraldehyde 3-phosphate dehydrogenase (GAPDH) antibody and HRP-labeled donkey anti-goat IgG antibody from Santa Cruz Biotechnology, Inc. (Dallas, TX); HRP-labeled goat antimouse IgG antibody from American Qualex International, Inc. (San Clemente, CA); and mouse monoclonal anti-Akt (pan) antibody and rabbit monoclonal anti-phosphorylated Akt antibody from Cell Signaling Technology, Inc. (Danvers, MA). SCADS inhibitor kit III was provided from the Screening Committee of Anticancer Drugs. All other chemicals and reagents were purchased from Sigma-Aldrich Corporation (St. Louis, MO).

Patients and tissue specimens. We retrospectively studied 95 patients who were diagnosed with NSCLC and who had undergone surgery between 1994 and 2001 at Nippon Medical School Hospital. None of the included surgical patients had received chemotherapy or radiation therapy before surgery. All cases were classified according to the UICC 7th TNM staging (27). Paraffin-embedded specimens were prepared for immunohis- tochemical analysis. The genetic profiles of driver oncogenes such as EGFR mutations were not examined, because all cases had been treated before the approval of EGFR-TKIs. The lung tissues from lung cancer patients were used only for immunohistochemical analysis. Immunohistochemical staining of the lung cancer tissue samples was carried out in accordance with the principles embodied in the Declaration of Helsinki, 2008. All included patients provided written informed consent for the use of their tissue specimens for medical research.

Immunohistochemistry. Paraffin-embedded tissue sections (3 $\mu \mathrm{m}$ ) were subjected to immunostaining using Histofine Simple Stain MAX PO (M) or (R) kits, as previously reported $(28,29)$. After deparaffinization, antigen retrieval for phosphorylated Akt antibody was performed at $121^{\circ} \mathrm{C}$ for $15 \mathrm{~min}$ in a sodium citrate buffer solution ( $\mathrm{pH}$ 6.0). For all antibodies, endogenous peroxidase activity was blocked by incubating sections for $30 \mathrm{~min}$ with $0.3 \%$ hydrogen peroxide in methanol. Sections were then incubated with monoclonal anti-nestin antibody (1:200 dilution), monoclonal anti-Akt (pan) antibody (1:100 dilution), monoclonal anti-phosphorylated Akt (Ser 473) antibody (1:50 dilution), or polyclonal anti-Sox 2 antibody (1:100 dilution). Bound antibodies were detected with Simple Stain MAX PO (M) or (R) reagent, using diaminobenzidinetetrahydrochloride chromogen as the substrate. Negative control studies were performed by omitting the primary antibodies. In a blinded manner, two investigators (K.N. and Y.M.) separately evaluated each specimen at x200 magnification. A sample was considered positive if staining was present in the cytoplasm of more than $30 \%$ of the tumor cells, regardless of staining intensity (29).

Lung adenocarcinoma cell lines. The cell lines A549 and RERF-LC-KJ were obtained from RIKEN BioResource Center (Ibaragi, Japan). PC-3 [the different cell line from the American Type Culture Collection (ATCC; Manassas, VA) CRL-1435] was obtained from the Health Science Research Resources Bank (Osaka, Japan). The PC-9, PC-14, and LC2/ad cell lines were obtained from Immuno-Biological Laboratories Co., Ltd. (Gunma, Japan). NCI-H1975 (no. CRL-5908, lot no. 3546434) and HCC827 (no. CRL-2868, lot no. 59389082) were obtained from ATCC. The cells were grown at $37^{\circ} \mathrm{C}$ in a humidified $5 \% \mathrm{CO}_{2}$ atmosphere. The cancer cells were cultured in RPMI-1640 medium containing $15 \%$ fetal bovine serum (FBS), except for H1975, which was grown in RPMI-1640 containing $10 \%$ FBS.

Quantitative reverse transcription-polymerase chain reaction ( $q R T-P C R)$. A total of $2.5 \times 10^{5}$ cells were seeded in $60-\mathrm{mm}$ dishes and incubated for $48 \mathrm{~h}$. Total RNA was extracted from cells with the FastPure RNA Kit, and $1 \mu \mathrm{g}$ was used for reverse transcription with the High Capacity cDNA Reverse Transcription kit, following the manufacturer's protocol. We performed qRT-PCR for nestin and 18S rRNA (as an internal standard) with the StepOnePlus Real-Time PCR system (Life Technologies) using specific primers and a TaqMan probe, as previously reported (30). Cycling conditions were as follows: $20 \mathrm{sec}$ at $95^{\circ} \mathrm{C}$, and then 40 cycles of $1 \mathrm{sec}$ at $95^{\circ} \mathrm{C}$ and $20 \mathrm{sec}$ at $60^{\circ} \mathrm{C}$. qRT-PCR results are expressed as the ratio of target mRNA to 18S rRNA. Gene expression levels were measured in triplicate. 
Construction of expression vector for nestin short hairpin RNA (nestin shRNA). To construct expression vectors for human nestin shRNA, we synthesized a DNA fragment that was flanked by the BamHI and HindIII sites and contained the sense target sequence for nestin (NM_006617; 5'-GAA-CAGGAT-CAG-ATG-ACA-T-3'), the hairpin loop sequence (5'-TAG-TGC-TCC-TGG-TTG-3'), and the corresponding antisense sequence. This fragment was inserted into the pBAsi-hU6 Neo DNA vector (18). The scrambled sequence (5'-TCT-TAA-TCG-CGT-ATA-AGG-C-3') was used as a negative control. Transfections of the nestin shRNA expression vector (Sh) and scrambled sequence-expressing vector (Sc) were performed using FuGene HD transfection reagent, according to the manufacturer's instructions. Briefly, H1975 cells $\left(1 \times 10^{5}\right.$ cells/well) were plated in 6-well plates and grown in $2 \mathrm{ml}$ of RPMI-1640 medium with $10 \%$ FBS. The vectors $(5 \mu \mathrm{g})$ were transfected into cells using $5 \mu \mathrm{l}$ of FuGene HD, and the cells were passaged and cultured with $1,000 \mu \mathrm{g} / \mathrm{ml}$ of geneticin. Cell lysates were collected, and the decreased nestin mRNA was confirmed using qRT-PCR.

Construction of nestin expression vector. The full-length nestin cDNA fragment was ligated to the 3 ' end of the human cytomegalovirus early promoter/enhancer in the eukaryotic expression vector pAcGFP1-N1 (18). Proper orientation of the insert was verified by DNA sequencing. Transfections of the nestin expression vector (Nes) and empty vector (EV) into PC-3 cells were performed using FuGene HD transfection reagent, with the above-described protocol for $\mathrm{Sh}$ and $\mathrm{Sc}$ vectors. To produce stably-transfected PC-3 cells, the cells were passaged and cultured with $1,000 \mu \mathrm{g} / \mathrm{ml}$ of geneticin. Cell lysates were collected, and the increased nestin mRNA levels were confirmed using qRT-PCR.

Transfection with nestin-targeting small-interfering RNA (nestin siRNA). Cells were seeded on $35-\mathrm{mm}$ dishes, and then transfected twice with the nestin siRNAs in serum-free RPMI-1640 medium using TransIT-si-QUEST transfection reagent (30). Briefly, each siRNA stock solution was mixed with TransIT-si-QUEST (2.0 $\mu \mathrm{l} /$ well) in serum-free medium, and incubated at room temperature for $15 \mathrm{~min}$. This siRNA-lipid complex was then added to cultured cells, which were incubated for $24 \mathrm{~h}$ at $37^{\circ} \mathrm{C}$. Next, the medium was replaced with fresh medium containing FBS, siRNA was administered a second time, and the treated cells were cultured for $48 \mathrm{~h}$ before being collected for analyses. Prior to this experiment, we transfected cells with the siRNAs once or twice at concentrations ranging from 5-20 nM, and used qRT-PCR to determine that the appropriate siRNA concentration was $10 \mathrm{nM}$.

Immunofluorescent staining and confocal laser microscopy. The same anti-nestin antibody used for the immunohistochemistry was employed for immunofluorescent staining. $\mathrm{H} 1975$ - and PC-3-derived cells ( $1 \times 10^{5}$ cells) were plated in 35-mm glass-bottomed dishes and incubated for $72 \mathrm{~h}$ at $37^{\circ} \mathrm{C}$ in a humidified $5 \% \mathrm{CO}_{2}$ atmosphere. Cells were fixed with $4 \%$ paraformaldehyde for $15 \mathrm{~min}$. The fixed cells were treated with $50 \mathrm{mM}$ glycine for $5 \mathrm{~min}, 0.1 \%$ Triton X-100 for $5 \mathrm{~min}$, and $10 \%$ donkey serum for $30 \mathrm{~min}$ at room temperature. The cells were then incubated with the anti-nestin antibody (1:50 dilution) in phosphate-buffered saline containing $1 \%$ bovine serum albumin overnight at $4^{\circ} \mathrm{C}$. Next, the cells were washed with phosphate-buffered saline, and incubated with Alexa 488-conjugated goat anti-mouse IgG for $1 \mathrm{~h}$. The cells were mounted with Vectashield mounting medium containing DAPI. Fluorescent images were acquired using a confocal laser scanning microscope Digital Eclipse TE 2000-E (Nikon Insteck Co., Ltd., Tokyo, Japan), and were analyzed using the confocal microscope Digital Eclipse C1 control software EZ-C1 version 2.30 (Nikon Insteck Co., Ltd.).

Cell proliferation assay. The growth rates of lung AD cells were analyzed using a non-radioactive cell proliferation assay (31). The H1975- and PC-3-derived cells were seeded at a density of $5 \times 10^{3}$ in 96-well plates in RPMI-1640 medium with 10 and $15 \%$ FBS, respectively. The cells were incubated at $37^{\circ} \mathrm{C}$ in a humidified $5 \% \mathrm{CO}_{2}$ atmosphere for 3 days for shRNA- or vector-transfected cells, and 5 days for inhibitor-treated cells. Then, the cells were incubated with WST-8 cell counting reagent for $4 \mathrm{~h}$ at $37^{\circ} \mathrm{C}$ and the optical density of the culture solution in the plate was measured at $450 \mathrm{~nm}$ using an ELISA plate reader (Bio-Rad, Hercules, CA). Experiments were performed in triplicate.

Time-lapse analysis. To confirm the effects of nestin on cell migration, we performed a time-lapse assay of single cell movement. Briefly, 1,000 cells/well were seeded onto 4-well glass-bottom dishes and grown for $48 \mathrm{~h}$. Cell movement was then monitored for $24 \mathrm{~h}$ using a Biostation IM (Nikon Insteck, Co., Ltd.), which photographed the cells every $5 \mathrm{~min}$. The total distances covered by individual cells within $24 \mathrm{~h}$ were determined using MetaMorph software 7.6 (Universal Image Corp., Ltd., Buckinghamshire, UK), as previously reported (32). Images were taken from four areas of each well at x200 magnification, and the movement of all cells in each field was analyzed. Approximately 50-100 cells in each well were analyzed for single-cell movement.

Cell invasion assays. To assess the effect of nestin on H1975 cell invasion through Matrigel, we used a modified Boyden chamber technique as previously reported (18). Briefly, cells were suspended in $500 \mu \mathrm{l}$ serum-free medium, and $1.0 \times 10^{5}$ cells were placed in the upper component of Matrigel-coated inserts. The lower compartment was filled with $750 \mu \mathrm{l}$ medium containing $10 \% \mathrm{FBS}$, and the cells were incubated at $37^{\circ} \mathrm{C}$ in a humidified $5 \% \mathrm{CO}_{2}$ atmosphere. After $8 \mathrm{~h}$, the cells on the bottom surface of the filter were fixed and stained with a Diff-Quick staining kit, and were counted under a light microscope. PC-3 cells were not appropriate for this study due to their extremely low motility.

Sphere-forming assays. To determine whether alteration of nestin expression levels affected the cancer stem cell (CSC)-like characteristics of AD cells, we performed sphere formation assays (16). PC-3 cells $\left(1.0 \times 10^{4}\right.$ cells/well) were plated in 24-well ultra-low attachment plates with serum-free medium supplemented with bFGF (10 ng/ml) and EGF $(20 \mathrm{ng} / \mathrm{ml})$. After 7 days, the number of spheres in each well was counted using a phase-contrast microscope (Eclipse TE2000-U; Nikon Insteck, Co., Ltd.). Experiments were performed in triplicate. 
A

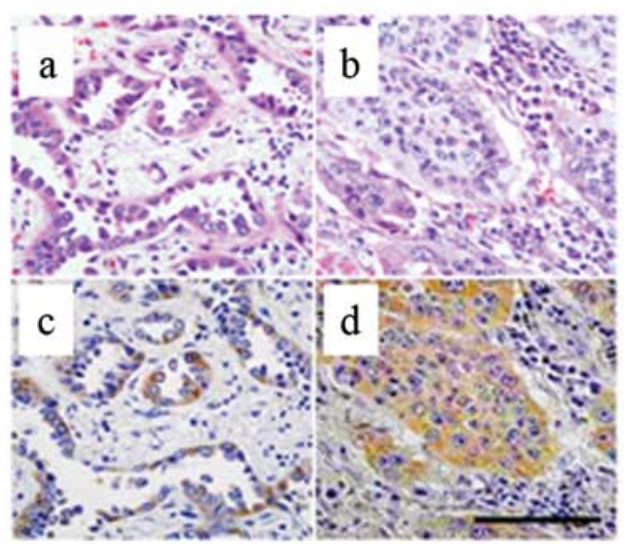

C

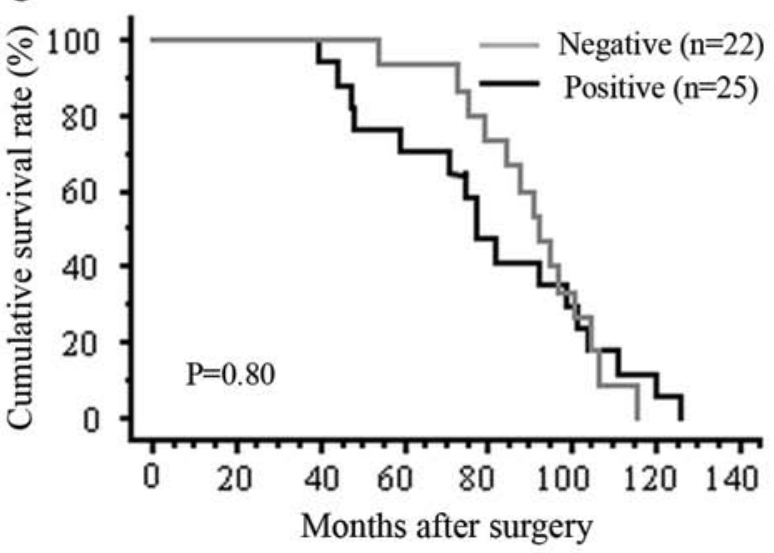

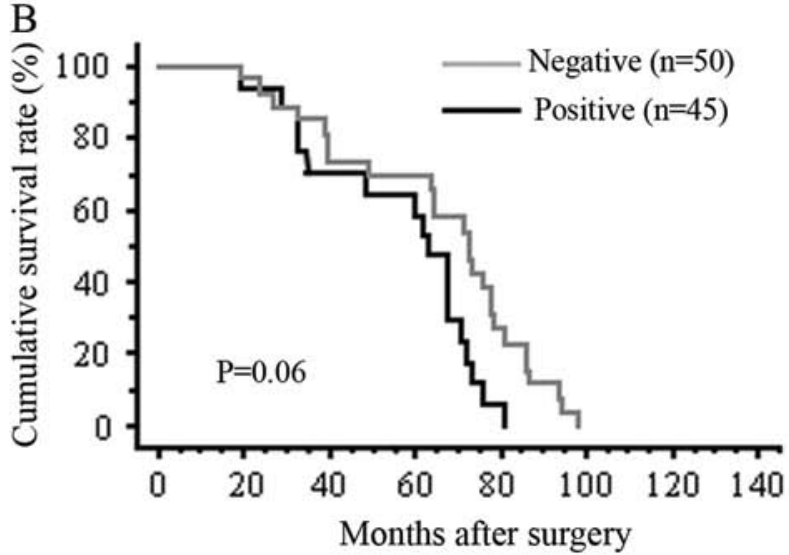

D

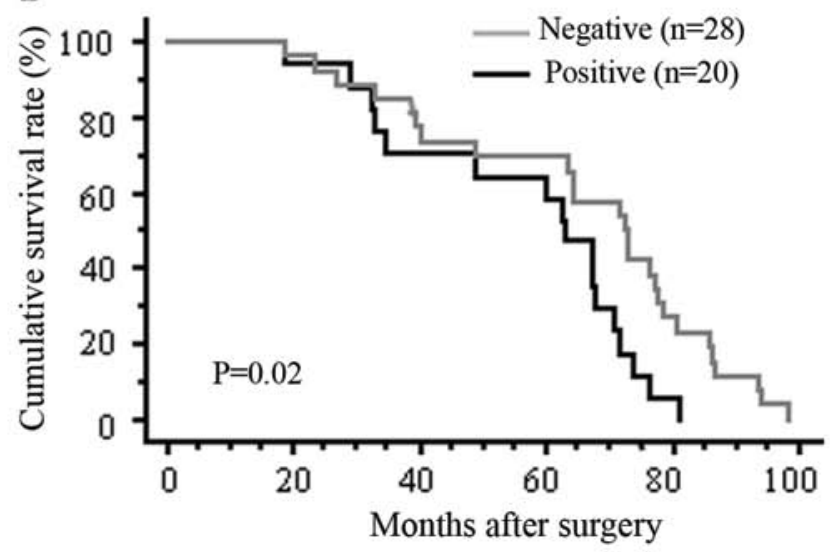

Figure 1. Nestin expression and survival analysis in non-small cell lung cancer (NSCLC). (A) H\&E and immunohistochemical staining for nestin in adenocarcinoma (AD; a and c, respectively) and squamous cell carcinoma (SCC; b and d, respectively). Scale bar, $100 \mu \mathrm{m}$. Kaplan-Meier analysis for (B) total NSCLC, (C) SCC subgroup, and (D) AD subgroup. Nestin expression was correlated with worse prognosis in AD (D, $\mathrm{p}=0.02)$.

Screening for nestin-related signaling pathways using an inhibitor kit. We screened for molecules that regulated nestin expression using the SCADS inhibitor kit III containing a total of 95 compounds in a 96 -well plate. PC-3 cells $\left(1.0 \times 10^{3}\right.$ cells/well) were seeded in a 96-well plate on day 1 , and each inhibitor was added at $5 \mu \mathrm{M}$ on day 3 . On day 5 , we examined the altered levels of nestin mRNA by performing direct qRT-PCR analysis of nestin using the TaqMan Fast Cells-to-CT kit.

Western blot analysis. Protein was extracted from cells using $2 \mathrm{M}$ thiourea buffer (33), and the lysates were centrifuged twice for $10 \mathrm{~min}$ at 3,000 rpm and once for $30 \mathrm{~min}$ at 15,000 rpm to pellet cell debris. The resulting supernatants were collected, and the protein concentration was measured using a Qubit fluorometer (Life Technologies). Lysates were subjected to sodium dodecyl sulfate-polyacrylamide gel electrophoresis (SDS-PAGE) using reducing conditions for each antibody. Immunoblotting was performed using mouse anti-nestin antibody (1:8,000 dilution), mouse anti-Akt (pan) antibody (1:2,000 dilution), rabbit anti-phosphorylated Akt (1:2,000 dilution), and rabbit anti-Sox 2 antibody (1:1,000 dilution). To assess lane loading, the membranes were also blotted with mouse anti-GAPDH antibody and mouse anti- $\beta$-actin antibody.
Statistical analysis. All quantitative data are presented as mean \pm standard deviation (SD), and were assessed using Student's t-test and the Tukey-Kramer test. The $\chi^{2}$ test and Fisher's exact test were used to analyze the correlations between nestin expression and clinicopathological features. Cumulative survival rates were calculated by the Kaplan-Meier method. The significance of differences in survival rate was analyzed by the log-rank test, with $\mathrm{p}<0.05$ considered significant in all analyses. Computations were performed using the StatView J version 4.5 software package (SAS Institute, Inc., Cary, NC).

\section{Results}

Immunohistochemical analysis of nestin in NSCLC specimens. Immunohistochemical analysis was performed to examine nestin expression in surgically resected NSCLC tissues. Positive nestin protein expression was detected in the cytoplasm of 20 of 48 AD cases (41.7\%) and 25 of 47 SCC cases (53.2\%) (Fig. 1A, Table I). Nestin immunoreactivity in NSCLC correlated with tumor size and lymph node metastasis $(p=0.02$, Table I). The nestin-positive and nestin-negative groups did not significantly differ in any other factors, including age, gender, tumor differentiation, patho- 
Table I. Immunohistochemistry of nestin in surgically treated non-small cell lung cancer cases $(n=95)$.

\begin{tabular}{|c|c|c|c|c|}
\hline & \multicolumn{2}{|c|}{ Nestin expression } & \multirow[b]{2}{*}{ Total } & \multirow[b]{2}{*}{ p-value } \\
\hline & $\begin{array}{l}\text { Positive } \\
(n=45)\end{array}$ & $\begin{array}{l}\text { Negative } \\
(n=50)\end{array}$ & & \\
\hline Age, years & & & & 0.21 \\
\hline$<65$ & 15 & 23 & 38 & \\
\hline$\geq 65$ & 30 & 27 & 57 & \\
\hline Gender & & & & 0.61 \\
\hline Men & 37 & 39 & 76 & \\
\hline Women & 8 & 11 & 19 & \\
\hline Histological type & & & & 0.26 \\
\hline Adenocarcinoma & 20 & 28 & 48 & \\
\hline Squamous cell carcinoma & 25 & 22 & 47 & \\
\hline Tumor differentiation & & & & 0.22 \\
\hline Well or moderate & 28 & 37 & 65 & \\
\hline Poor & 17 & 13 & 30 & \\
\hline Pathological TNM staging & & & & $0.02^{\mathrm{a}}$ \\
\hline Tis, 1 & 10 & 23 & 33 & \\
\hline $\mathrm{T},>1$ & 35 & 27 & 62 & \\
\hline No & 31 & 44 & 75 & $0.02^{\mathrm{a}}$ \\
\hline $\mathrm{N},>0$ & 14 & 6 & 20 & \\
\hline Pathological staging & & & & 0.22 \\
\hline $0, \mathrm{I}$ & 30 & 39 & 69 & \\
\hline II, III & 15 & 11 & 26 & \\
\hline Lymph duct invasion & & & & 0.06 \\
\hline Positive & 22 & 15 & 37 & \\
\hline Negative & 23 & 35 & 58 & \\
\hline Vascular invasion & & & & 0.49 \\
\hline Positive & 23 & 22 & 45 & \\
\hline Negative & 22 & 28 & 50 & \\
\hline Intrapulmonary metastasis & & & & 0.34 \\
\hline Positive & 0 & 1 & 1 & \\
\hline Negative & 45 & 49 & 94 & \\
\hline Pleural invasion & & & & 0.20 \\
\hline Positive & 22 & 18 & 40 & \\
\hline Negative & 23 & 32 & 55 & \\
\hline
\end{tabular}

$\chi^{2}$ test, ${ }^{\mathrm{a}} \mathrm{p}<0.05$.

logical staging, lymphovascular invasion, vascular invasion, intrapulmonary metastasis and pleural invasion. To explore the therapeutic potential of targeting nestin, postoperative survival was evaluated, although the number of patients was small. Kaplan-Meier analysis showed no statistical differences in overall survival rates between nestin-positive and nestin-negative groups among all NSCLC (Fig. 1B) or within the SCC subpopulation (Fig. 1C). However, within the AD subpopulation, the overall survival rates significantly differed between nestin-positive and nestin-negative groups $(\mathrm{p}=0.02$; Fig. 1D), indicating that nestin expression might correlate with poorer survival in AD.

Nestin expression in AD cell lines and shRNA transfection. We next confirmed nestin expression levels in human lung AD cell lines by qRT-PCR (Fig. 2A). H1975 cells showed the highest levels of nestin mRNA, and PC-3 expressed moderate
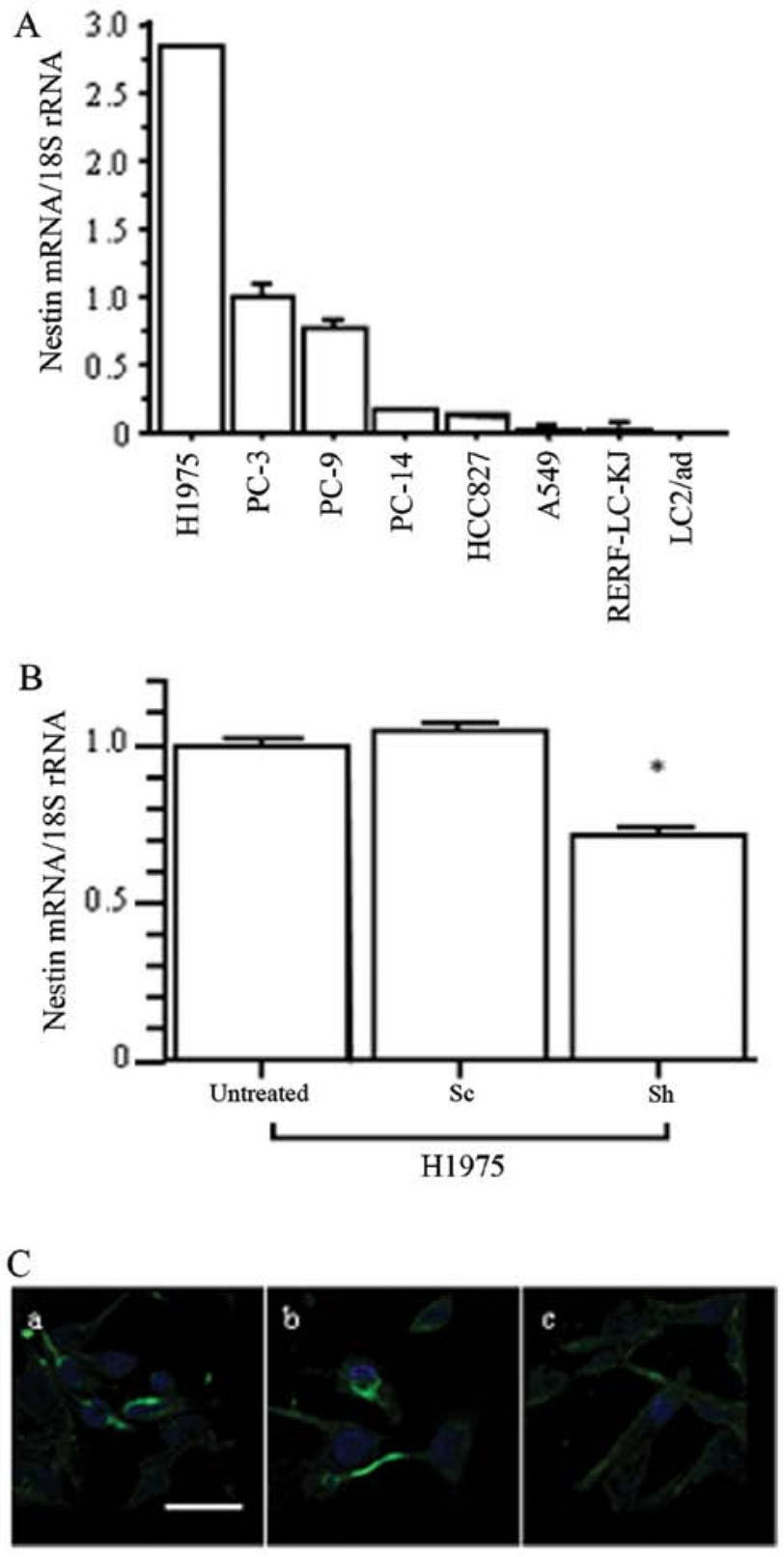

Figure 2. Nestin expression in lung adenocarcinoma cell lines and with nestin knockdown by shRNA. (A) Relative levels of nestin mRNA expression in lung adenocarcinoma cell lines. (B) Relative expression levels of nestin mRNA expression in H1975 cells, showing that nestin shRNA (sh)-transfected H1975 cells suppressed nestin mRNA expression compared with the untreated and scrambled sequence (Sc)-transfected H1975 cells. ${ }^{*} \mathrm{p}<0.05$ vs. untreated and Sc cells. (C) Immunofluorescent staining for nestin protein in (a) untreated, (b) Sc and (c) Sh cells. Green, nestin; blue, DAPI. Scale bar, $50 \mu \mathrm{m}$.

nestin levels. To examine the effects of nestin inhibition in AD cells, we established nestin shRNA-transfected H1975 (Sh) cells. qRT-PCR showed that nestin mRNA expression was significantly decreased in Sh cells compared to in untreated and scrambled sequence-expressing vector-transfected (Sc) cells ( $<<0.05$; Fig. 2B), but the Sh cells exhibited no characteristic morphological changes. Immunofluorescent staining confirmed decreased levels of nestin protein expression in Sh cells compared to untreated and Sc cells (Fig. 2C). Thus, H1975 cells were used in the following experiments to examine the inhibitory effects of nestin on AD cell behavior. 

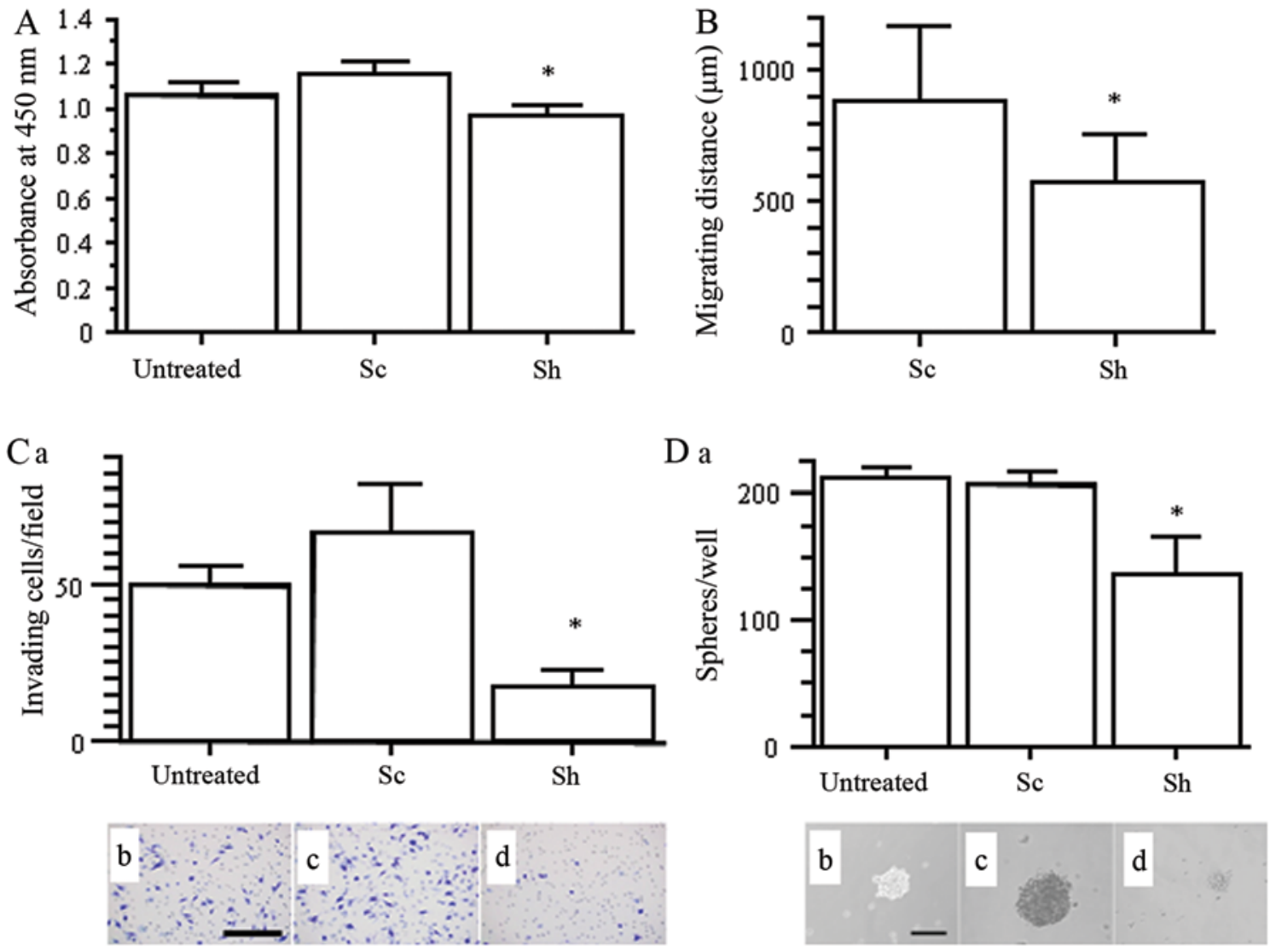

Figure 3. Effects of nestin shRNA on cancer cell growth, migration, invasion, and sphere formation in H1975 cells. (A) WST-8 cell growth assay. " untreated and Sc cells. (B) Migration distance over $24 \mathrm{~h}$ determined by time-lapse analysis. "p $<0.05 \mathrm{vs.} \mathrm{Sc} \mathrm{cell.} \mathrm{(C)} \mathrm{Cell} \mathrm{invasion} \mathrm{using} \mathrm{Matrigel-coated} \mathrm{Boyden}$ chamber assay. (a) The number of invading cells per field. "p $<0.05$ vs. untreated and Sc cells. (b, c and d) Diff-Quick staining for untreated, Sc and Sh cells, respectively. Scale bar, $100 \mu \mathrm{m}$. (D) (a) The number of spheres per well. "p<0.05 vs. untreated and Sc cells. (b, c and d) Phase contrast images of the spheres in untreated, Sc and Sh cells, respectively. Scale bar, $100 \mu \mathrm{m}$.

Cell growth, migration, invasion and sphere formation assays in nestin shRNA-transfected H1975 cells. In order to clarify the effects of nestin downregulation on cell growth, migration, invasion and stemness of lung adenocarcinoma cells, we used H1975 untreated, Sc and Sh cells. Compared to untreated and Sc cells, Sh cells exhibited significantly decreased cell proliferation ( $p<0.05$; Fig. $3 \mathrm{~A}$ ) and cell migration in the time-lapse assay $(\mathrm{p}<0.05$; Fig. 3B). The Boyden chamber assay showed that Sh cell invasion through Matrigel was markedly inhibited ( $p<0.05$ vs. untreated and Sc; Fig. 3C). We also analyzed sphere formation of $\mathrm{H} 1975$ to determine CSC properties. In the ultra-low attachment plates, Sh cells exhibited remarkably decreased sphere size and number compared with in untreated and Sc-transfected H1975 cells ( $\mathrm{p}<0.05$; Fig. 3D). Overall, our results showed that inhibition of nestin in H1975 cells resulted in reduced cell proliferation, migration, invasion and sphere-forming ability.

Cell growth, migration and sphere formation assays in nestin gene-transfected PC-3 cells. We also established nestin expression vector-transfected PC-3 (PC-Nes) cells to examine the effects of upregulation of nestin on $\mathrm{AD}$ cell behavior. Transfection with PC-Nes significantly enhanced nestin expression at both the mRNA and protein levels compared to the untreated and empty vector-transfected PC-3 (EV) cells
( $<<0.05$; Fig. 4A and B). Stable transfection of the nestin gene resulted in increased $\mathrm{PC}-3$ cell proliferation and migration $(\mathrm{p}<0.05$; Fig. 4C and D). PC-Nes cells also showed higher sphere formation capability regarding the number of spheres $(\mathrm{p}<0.05$ vs. untreated and EV; Fig. 4E). Overall, increased nestin expression in PC-3 cells resulted in the opposite effects on cell behavior, when compared to the effects of decreased nestin expression in H1975 cells.

Screening analysis using chemical compounds to clarify the candidate molecules of signaling pathway that regulate nestin expression in lung adenocarcinoma cells. Next, we searched for upstream molecules of nestin using the SCADS Inhibitor Kit III, which included 95 chemical compounds that each inhibited a specific molecular target (34). In PC-3 cells, several compounds suppressed nestin mRNA expression, including cyclin-dependent kinase (CDK) inhibitors, as expected from previous reports $(35,36)$. Akt inhibitor IV led to a $72 \%$ reduction of nestin expression compared to in the DMSO-treated negative control. Akt is located downstream of the EGFR pathway $(37,38)$, and Akt regulates Sox 2 expression and the self-renewal of CSC-like cells in NSCLC (39). Sox 2 is also known to be a transcriptional factor for nestin (40). We confirmed co-expression of nestin, Akt, phosphorylated Akt (p-Akt), and Sox 2 in serial tissue sections from AD 
A
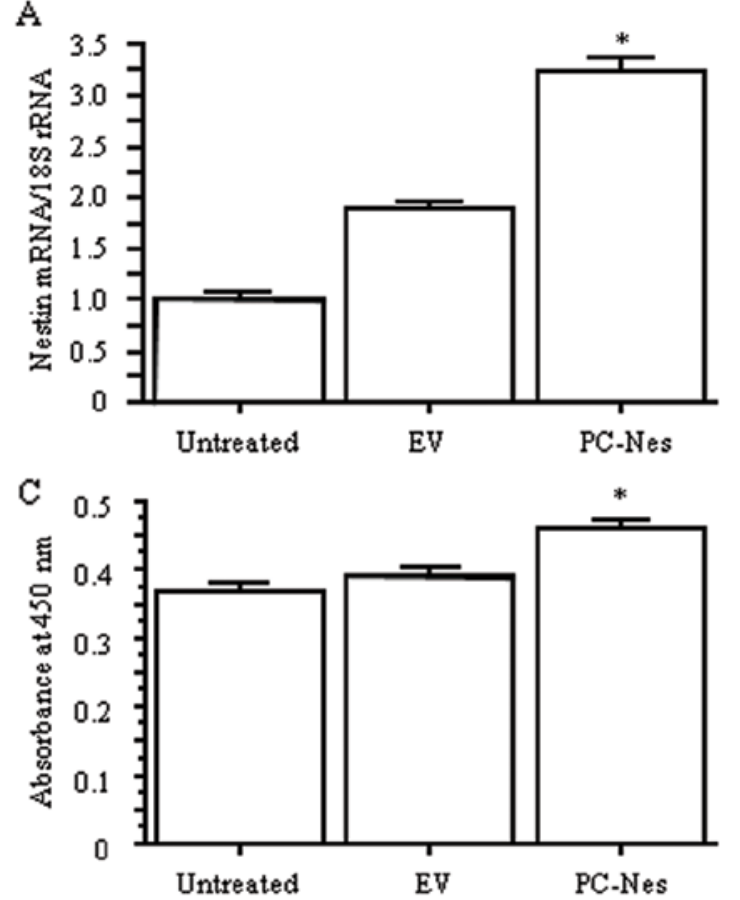

E

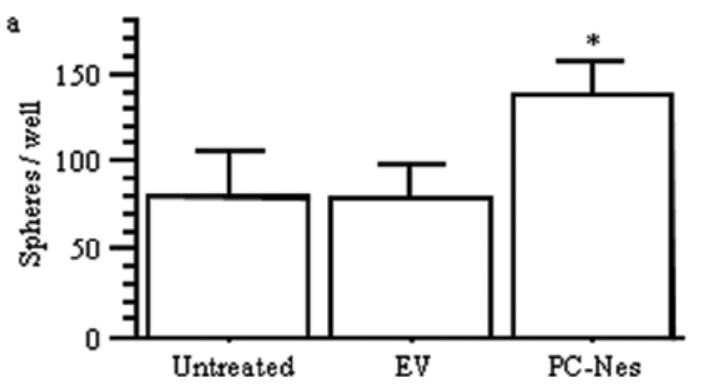

B

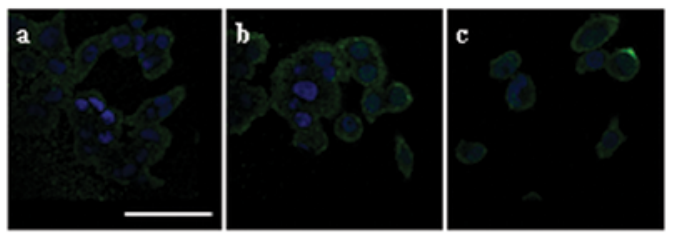

D

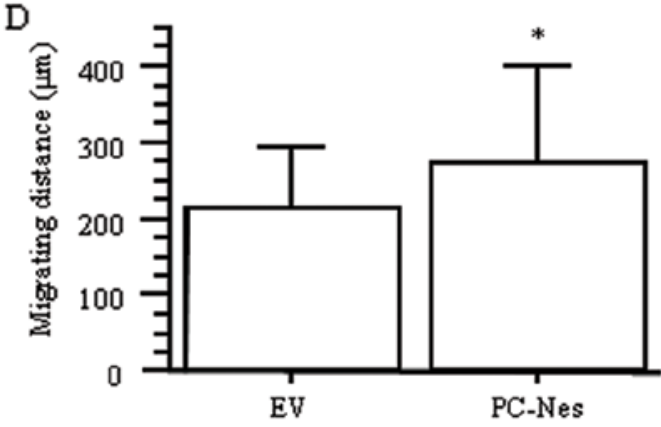

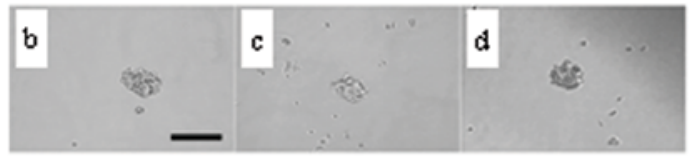

Figure 4. The effects of nestin gene transfection on proliferation, migration, and sphere formation in PC-3 cells. (A) Relative nestin mRNA expression levels in nestin expression vector (PC-Nes)- and empty vector (EV)-transfected cells. * p $<0.05$ vs. untreated and EV cells. (B) Immunofluorescent staining for nestin in (a) untreated, (b) EV and (c) PC-Nes cells, respectively. Green, nestin; blue, DAPI. Scale bar, $50 \mu \mathrm{m}$. (C) WST-8 cell growth assay. "p<0.05 vs. untreated and EV cells. (D) Migration distance over $24 \mathrm{~h}$ determined by time-lapse analysis. "p<0.05 vs. EV cells. (E) (a) The number of spheres per well. * $<<0.05$ vs. untreated and EV cells. (b, c and d) Phase contrast images of spheres in (b) untreated, (c) EV and (d) PC-NES cells. Scale bar, $100 \mu \mathrm{m}$.

cases (Fig. 5). Thus, we focused further experiments on Akt inhibitor IV to clarify the relationship between Akt, Sox 2 and nestin in AD cells.

Nestin expression is regulated via Akt/Sox2 signaling. Concordant with the results of screening analysis of nestin regulatory pathway using PC-3 cells with chemical compounds, qRT-PCR analysis and immunofluorescent staining confirmed the effective inhibition of nestin mRNA and protein expression by Akt inhibitor IV in $\mathrm{H} 1975$ and PC-3 cells ( $\mathrm{p}<0.05$ vs. DMSO-treated cells; Fig. 6A and B). Then we investigated changes in the expression of signaling pathway molecules, including p-Akt, Akt and Sox2. Akt inhibitor IV decreased the expression levels of Akt, p-Akt, and Sox 2 in both H1975 and PC-3 cells (Fig. 6C). On the other hand, transfection of nestintargeting siRNAs (siRNA-A and siRNA-B) into H1975 cells resulted in dramatically decreased expression levels of nestin mRNA and protein compared with the untreated and negative control siRNA (siControl)-transfected H1975 cells ( $<<0.05$;
Fig. 7A and B). In contrast, nestin siRNAs did not decrease the expression levels of p-Akt, Akt or Sox 2 (Fig. 7C). These results indicate that Akt is located upstream of nestin, and that Akt/ Sox 2 signaling regulates nestin expression.

Cell growth, migration and invasion assays under Akt inhibitor IV administration. Concordant with the result of nestin downregulation, Akt inhibitor IV inhibited cell proliferation of H1975 cells ( ${ }^{*}$ p<0.05 vs. DMSO-treated cells; Fig. 8A). Inhibition of Akt significantly inhibited the migration of $\mathrm{H} 1975$ cells compared with DMSO-treated cells ( $\mathrm{p}<0.05$; Fig. 8B), and Boyden chamber assays confirmed that Akt inhibitor IV decreased invasion of H1975 cells (Fig. 8C).

Inhibitory effects of Akt inhibitor IV on nestin expression in nestin gene-transfected PC-3. Comparative studies showed that among the three tested cell signaling inhibitors, Akt inhibitor IV, p38 inhibitor (SB203580), and MEK 1/2 inhibitor (U0126), only Akt inhibitor IV significantly inhibited nestin 


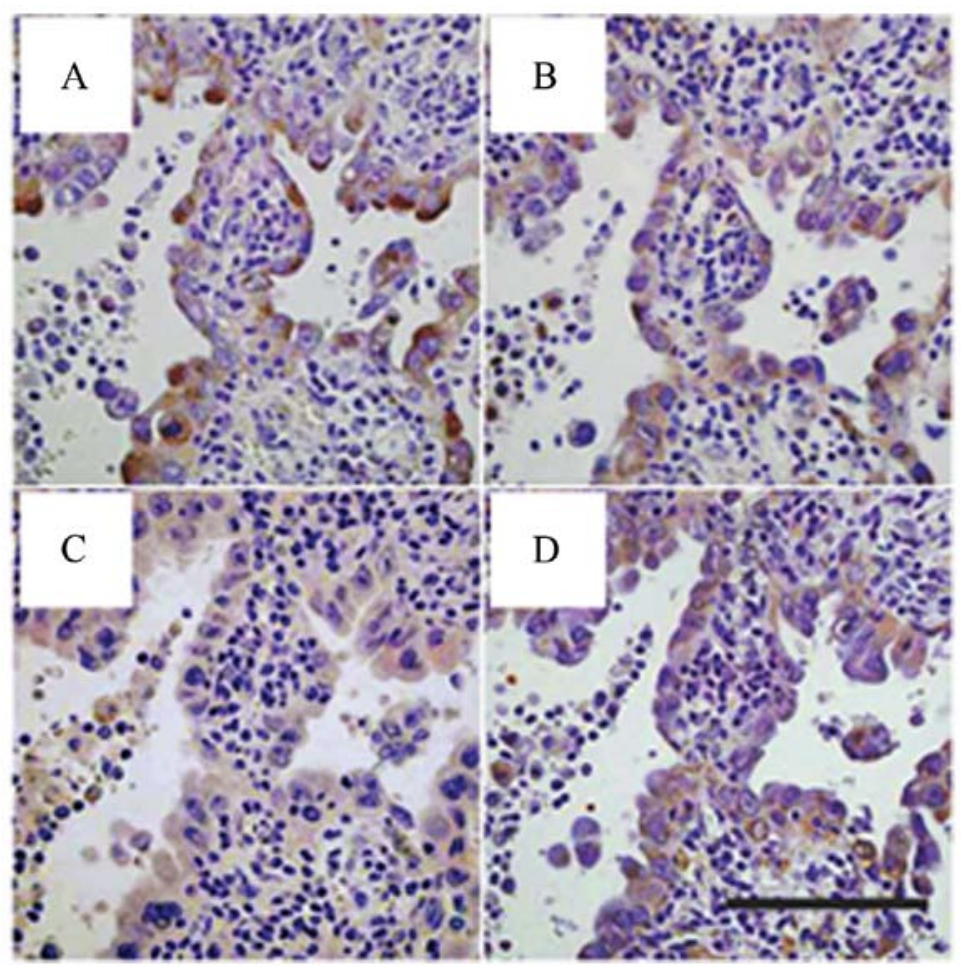

Figure 5. Immunohistochemical analysis on the relationship among nestin, Akt, p-Akt and Sox2. Immunohistochemical staining for nestin (A) and for signaling pathway molecules related to nestin [(B) Akt, (C) p-Akt and (D) Sox2] in human adenocarcinoma tissues. Scale bar, $100 \mu \mathrm{m}$.

expression in $\mathrm{H} 1975$ and PC-3 cells ( $\mathrm{p}<0.05$ vs. untreated and DMSO-treated groups; Fig. 9A and B). Next, we evaluated the effects of these inhibitors on nestin gene-transfected PC-3 cells (Fig. 9C). Stably nestin gene-transfected PC-Nes cells showed significantly increased nestin expression compared with the untreated and EV cells ( ${ }^{*} \mathrm{p}<0.05$; Fig. 9C). In PC-Nes cells, only Akt inhibition resulted in nestin downregulation $\left({ }^{\S} \mathrm{p}<0.05\right.$ vs. PC-Nes+/-DMSO; Fig. 9C).

We also evaluated sphere formation in PC-Nes cells following treatment with each inhibitor. PC-Nes cells exhibited significantly enhanced sphere formation (in both size and number) compared with DMSO-treated and EV cells $\left({ }^{*} \mathrm{p}<0.05\right.$; Fig. 9D and E). Compared to SB203580 and U0126, Akt inhibitor IV more markedly suppressed this increased sphere formation in PC-Nes cells $\left({ }^{\ddagger} \mathrm{p}<0.05\right.$ vs. PC-Nes cells with SB203580 or U0126; Fig. 9D and E). Akt inhibitor IV-treated PC-Nes cells also exhibited reduced sphere formation compared to DMSO-treated cells and EV cells ( $\mathrm{p}<0.05$; Fig. 9D and E). These findings indicated that Akt inhibitor IV effectively overcame the enhanced sphere formation induced by nestin upregulation. Overall, the Akt-Sox2-nestin pathway regulates cell proliferation, migration, invasion and sphere formation in lung $\mathrm{AD}$.

\section{Discussion}

Our present results showed that nestin regulates growth, migration, invasion and stemness of lung $\mathrm{AD}$, and that the Akt/Sox 2 pathway regulates nestin expression and functions. To the best of our knowledge, this is the first report to elucidate the detailed functions and signaling regulation mechanism of nestin in lung cancer. These findings will help develop new therapies to target nestin in lung cancers.

Akt is located downstream of EGFR, a well-known molecular target in AD. Previous immunohistochemical analysis of NSCLC biopsy specimens revealed Akt overexpression in 62\% and phosphorylated Akt in 44\% (41), and constitutional Akt activation in NSCLC cells promotes survival and resistance to chemotherapy and radiation (37). Akt also reportedly regulates Sox 2 expression and self-renewal of CSC-like cell sub-populations in NSCLC (39). Sox2 is a key transcription factor in both embryonic stem cells and induced pluripotent stem cells, and is also expressed in various cancers (42). Sox 2 overexpression reportedly correlates with stemness, augmentation of tumorigenicity, and poorer prognosis in lung AD $(43,44)$. Moreover, the enhancer region of the nestin gene has been shown to contain a Sox 2 binding site (40). Our study demonstrated that inhibition of Akt and p-Akt by Akt inhibitor IV resulted in downregulation of Sox 2 and nestin, and that siRNA targeting nestin did not affect the expression levels of Akt, p-Akt or Sox2. These observations clarified the nestin regulating pathway via $\mathrm{Akt} / \mathrm{Sox} 2$ and the therapeutic potential of targeting nestin. Together, these findings highlight and explain the significance of upstream nestin-regulating mechanisms in lung AD. In the present study, we used two types of lung AD cell lines that each have a different EGFR gene status: PC-3 has no activation of EGFR signaling (45), whereas H1975 harbors exon 19 deletion and T790M mutation in EGFR (46). We did not observe any conflicting cell behavior between these two types of AD cells when nestin expression was increased or decreased; thus, we suggest that EGFR mutation status does not affect the roles of nestin in AD cells. However, the relationship between nestin 

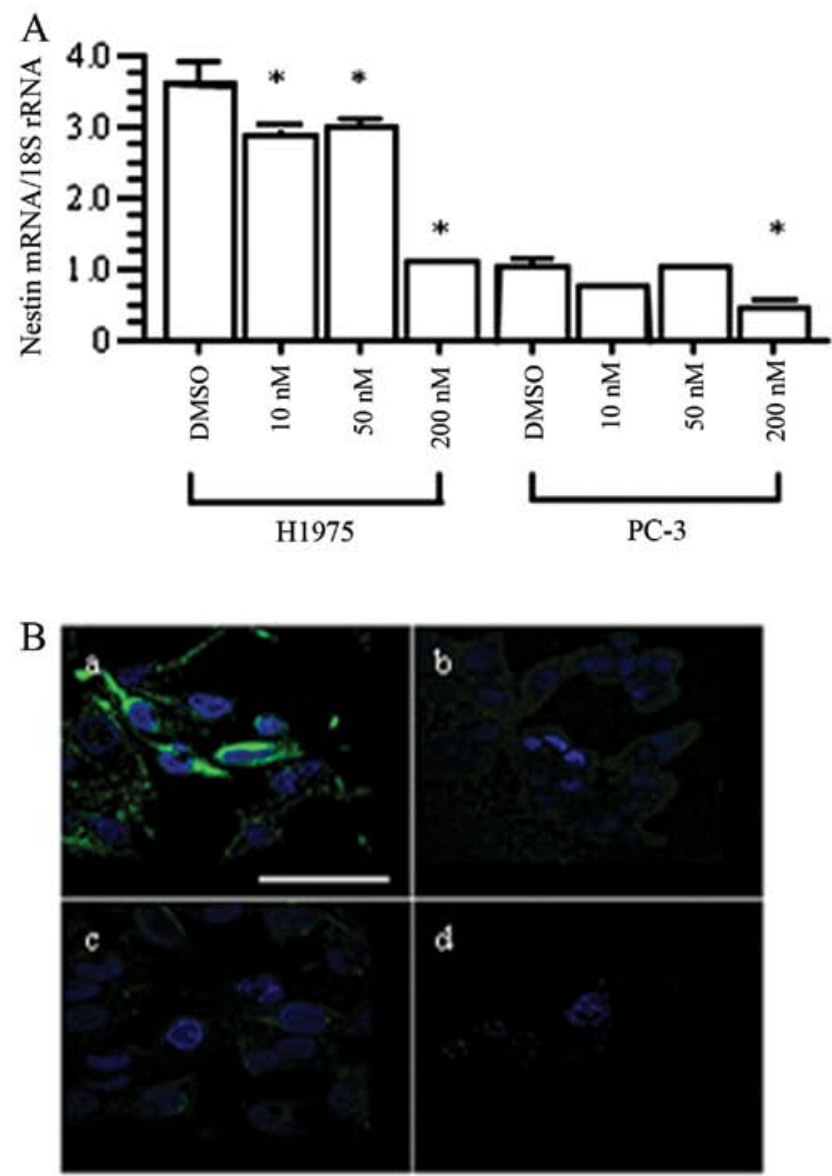

C

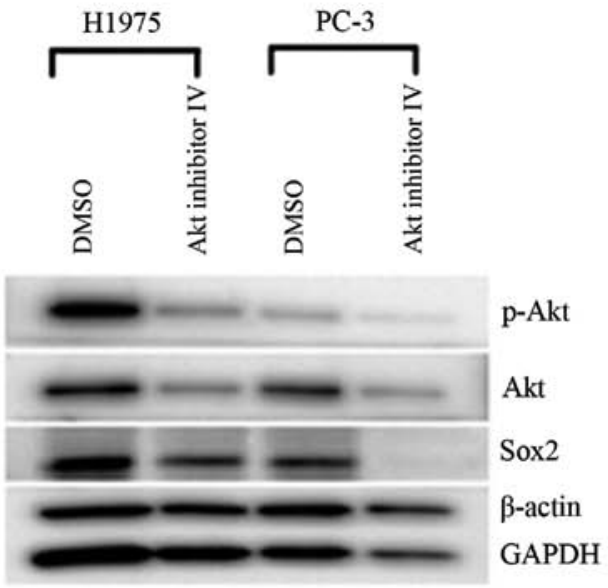

Figure 6. Pathway analysis of nestin regulatory signaling using Akt inhibitor IV. (A) Relative nestin mRNA expression levels in H1975 and PC-3 cells under Akt inhibitor IV administration. " $\mathrm{p}<0.05$ vs. DMSO-treated control cells. (B) Immunofluorescent staining of nestin protein in $\mathrm{H} 1975$ and PC-3 cells. (a) DMSO-treated H1975; (b) Akt inhibitor IV-treated H1975; (c) DMSO-treated PC-3; and (d) Akt inhibitor IV-treated PC-3. Green, nestin; blue, DAPI. Scale bar, $50 \mu \mathrm{m}$. (C) Western blot analysis for p-Akt, Akt and Sox 2 , with $\beta$-actin and GAPDH used as loading controls.

expression status and resistance to EGFR-TKIs requires further investigation.

Several groups have confirmed that nestin correlates with poorer postoperative prognosis in patients diagnosed with NSCLC, including AD, SCC and large cell carcinoma (21-24). Here we confirmed that nestin might be related to

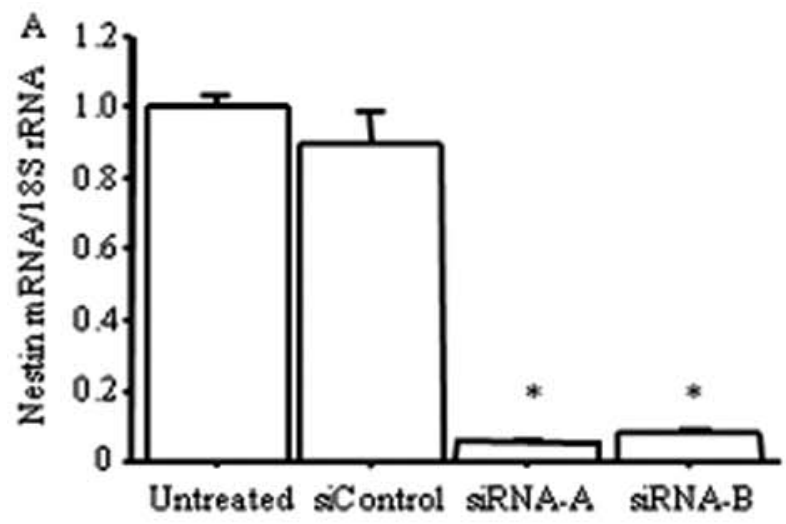

B
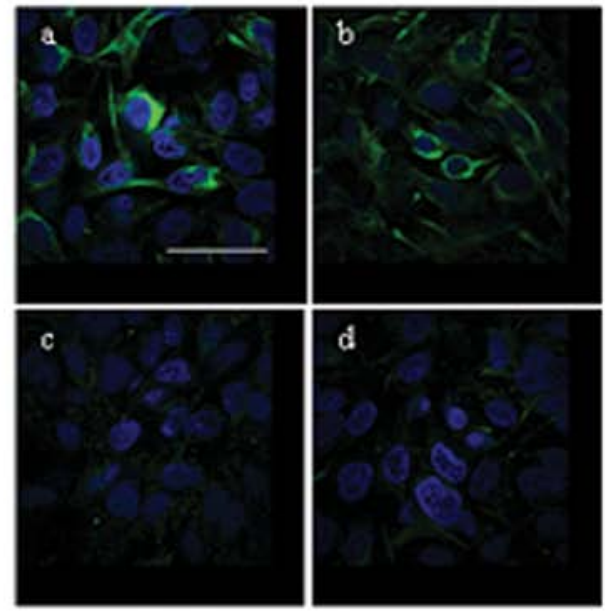

C

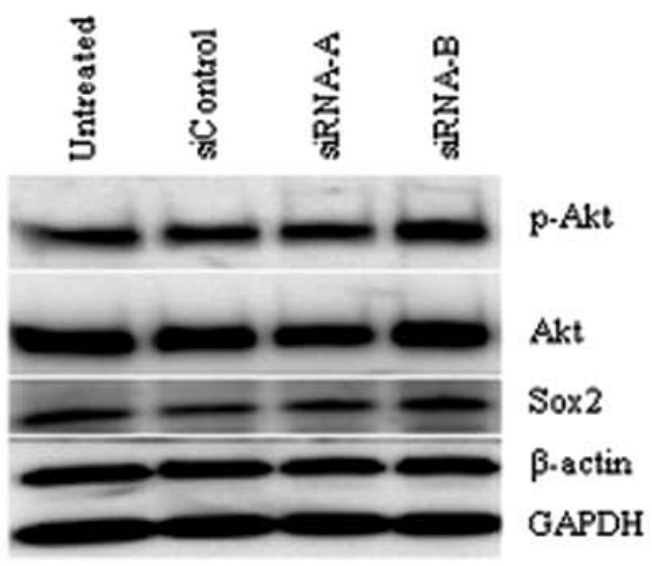

Figure 7. Pathway analysis of nestin regulatory signaling using nestin siRNA. (A) Relative expression levels of nestin mRNA expression in H1975 cells, showing that nestin siRNA (siRNA-A and siRNA-B) suppressed nestin mRNA expression compared with in untreated and negative control siRNA (siControl)-transfected H1975 cells. "p<0.05 vs. untreated and siControl cells. (B) Immunofluorescent staining for nestin protein in siRNA-transfected H1975 cells. (a) Untreated cells; (b) siControl-transfected cells; (c) siRNA-A transfected cells; and (d) siRNA-B transfected cells. Green, nestin; blue, DAPI. Scale bar, $50 \mu \mathrm{m}$. (C) Western blot analysis for p-Akt, Akt, and Sox 2 in nestin siRNA-transfected H1975 cells. $\beta$-actin and GAPDH were used as loading controls.

shorter postoperative survival in patients diagnosed with AD. Nestin expression was also correlated to tumor size and LN metastasis. Moreover, we found that nestin inhibition induced 

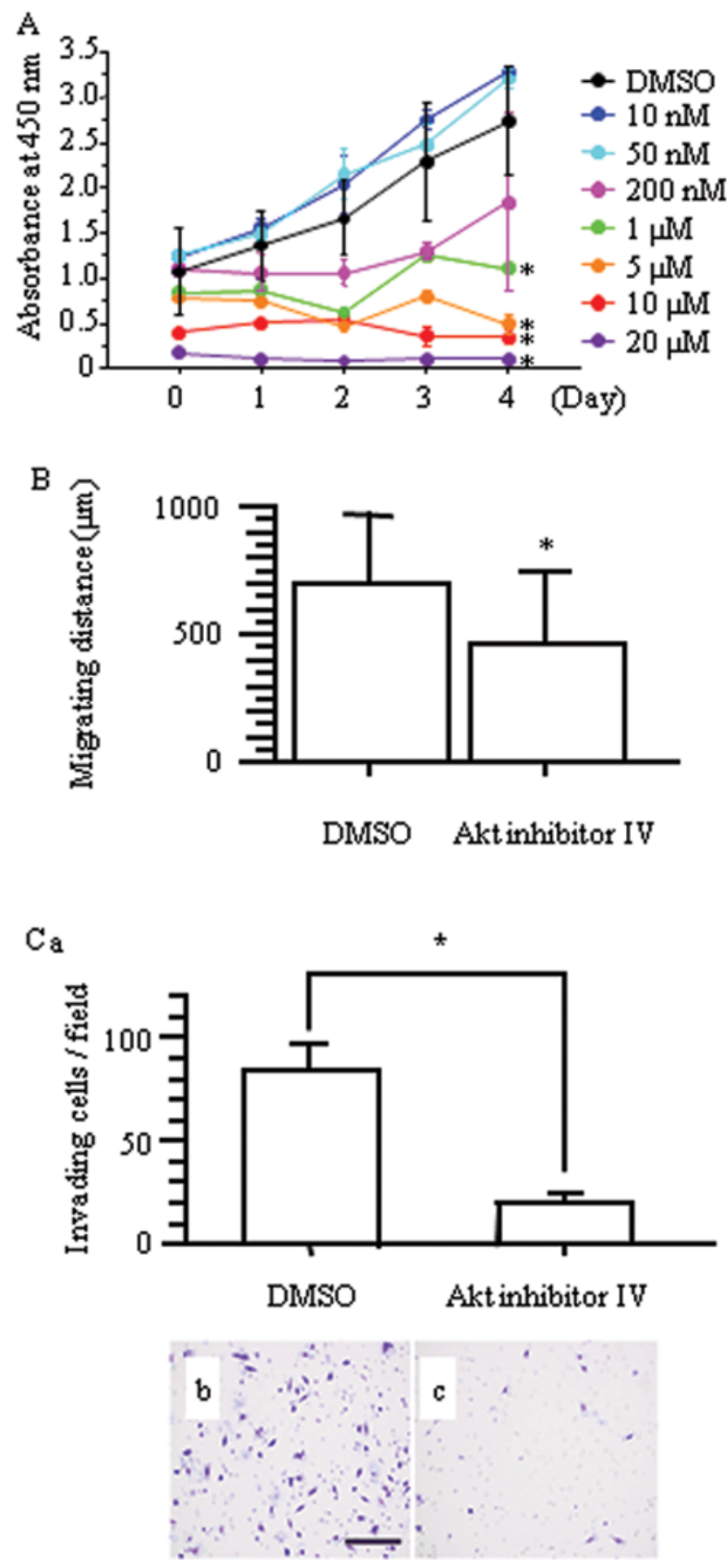

Figure 8. Effects of Akt inhibitor IV on proliferation, migration and invasion of H1975 and PC-3 cells. (A) WST-8 cell growth assay in H1975 cells. "p $<0.05$ vs. DMSO-treated control cells. (B) Migration distance of H1975 cells over $24 \mathrm{~h}$ determined by time-lapse analysis. * $\mathrm{p}<0.05$. (C) Cell invasion in Akt inhibitor IV-treated H1975 cells evaluated by Matrigel-coated Boyden chamber assay. (a) The number of invading cells per field. * $\mathrm{p}<0.05$ vs. DMSO-treated cells. (b and c) Diff-Quick staining for DMSO-treated and Akt inhibitor-IV treated cells, respectively. Scale bar, $100 \mu \mathrm{m}$. ${ }^{*} \mathrm{p}<0.05$. Scale bar, $100 \mu \mathrm{m}$.

anticancer effects (including anti-proliferation, migration and invasion) as well as suppressed sphere formation. Sphere formation ability represents the CSC property in various cancers, including NSCLC (47). CSCs, defined as a subpopulation that can self-renew and maintain the tumor presence (48), are also characterized by resistance to radiation and chemotherapy $(49,50)$. Several markers have been proposed to identify CSCs in NSCLC, including CD133 (49), ATP-binding cassette subfamily G member-2 (ABCG2) (51), aldehyde dehydrogenase-1 (ALDH-1) (52) and Hoechst side population (51). However, these markers are not sufficiently sensitive and specific to CSCs (53), possibly reflecting the heterogeneity of each tumor, histological subtype and individual (54). Here we showed that nestin upregulation induced increased sphere formation, while nestin downregulation (by both shRNA and Akt inhibition) resulted in decreased sphere forming ability. These findings indicate that nestin is a key regulator of CSCs in AD. Recent therapeutic advances have led to the molecular targeting therapies that inhibit driver oncogenes; however, these therapies inevitably face acquired resistance, resulting in unfavorable outcomes in AD. Nestin-targeting therapy may eradicate $\mathrm{CSCs}$ in $\mathrm{AD}$; thus, suppressing relapse and resistance against chemotherapy and molecular-directed therapy targeting driver oncogenes.

The results of our screening assay confirmed that nestin expression was decreased by some chemical compounds that target specific signaling molecules, including several compounds that specifically inhibit Akt. The chemical agent that strongly decreased nestin expression was Akt inhibitor IV, a cell-permeable compound that inhibits Akt phosphorylation/activation. Akt inhibitor IV presumably targets the ATP binding site of a kinase that is upstream of Akt but downstream of phosphatidylinositol-3 kinase (PI3K), resulting in blockade of the Akt-mediated nuclear export of forkhead box O1 (FOXO1) to the cytoplasm (55). FOXO1 is a transcriptional regulator of the G1/S checkpoint and of apoptosis. Loss of FOXO1 activity that is induced by phosphorylation via Akt signaling impairs cell cycle arrest, resulting in unlimited proliferation (56). EGFR-TKI resistance is driven by Akt activation, and can be overcome by decreasing Akt signaling with Akt inhibitors, resulting in FOXO1 reactivation or expression (57). FOXO1 is reported to control Sox 2 expression (58). Therefore, inhibition of FOXO1 by Akt inhibitor IV might also promote nestin downregulation via suppression of Sox 2 signaling.

In our screening assay using chemical compounds, we also found that nestin expression was strongly inhibited by Akt inhibitor VIII, the activity of which is reportedly pleckstrin homology (PH) domain-dependent (59). In contrast, nestin mRNA level was only slightly decreased by Akt inhibitor XI, which directly affects Akt but not the level of p-Akt. The relationship between the inhibitory effect on nestin and the mechanism of Akt inhibition for each Akt inhibitor remains unclear, but further investigation of the signaling pathway that connects Akt with nestin might reveal an appropriate approach to Akt inhibition that enhances nestin downregulation. We have also confirmed the nestin-inhibiting ability of compounds that inhibit cell cycle and mitosis, such as cdk1/2 inhibitor III and cdk2/9 inhibitor. Thus, nestin is thought to play important roles in the cell cycle of tumor cells, and cell cycle-targeted therapies via downregulation of nestin and its upstream molecules are promising for the development of new anticancer drugs.

In this study, we confirmed the expression of nestin in NSCLC and its correlation with poor survival in surgical patients with AD. Nestin inhibition in AD cell lines resulted in decreased proliferation, migration, invasion and sphere 
A

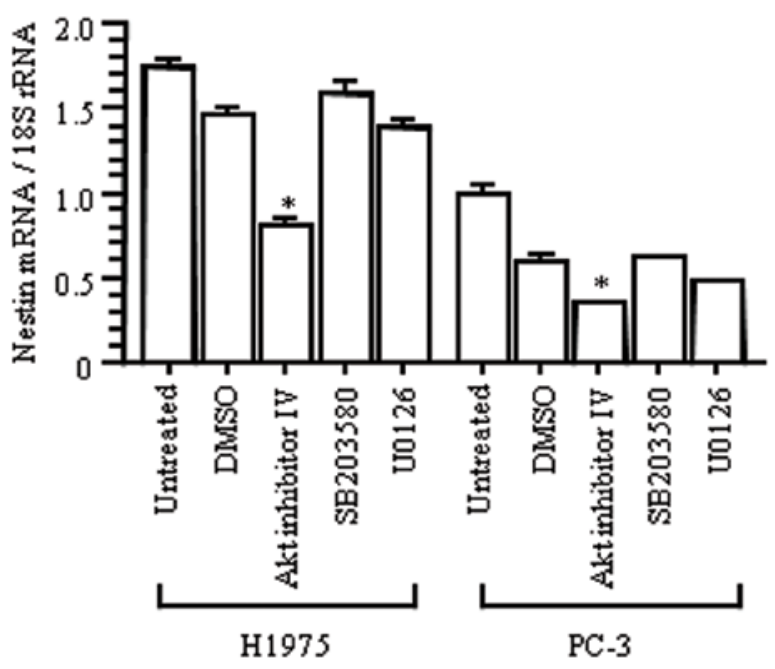

B

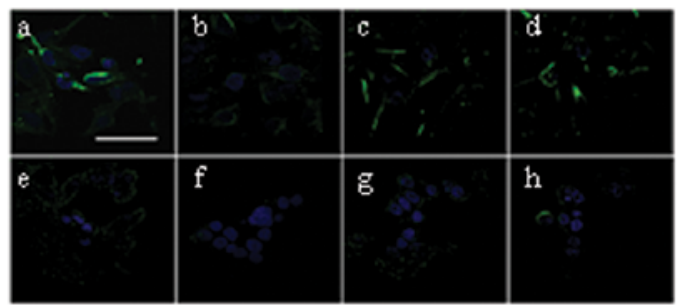

D

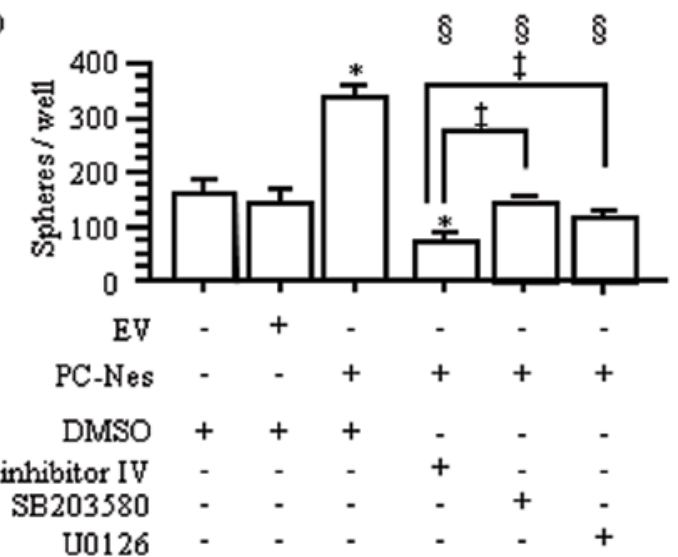

E

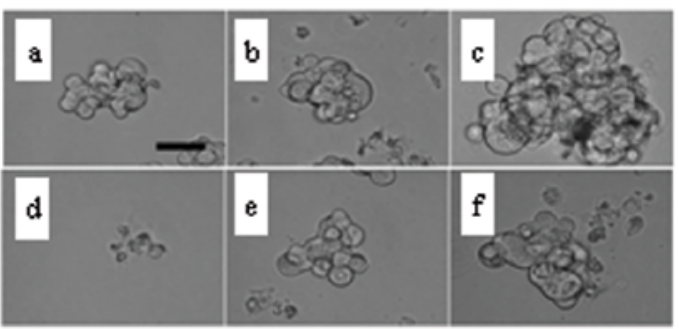

Figure 9. Effects of Akt, p38 MAP kinase and MEK 1/2 inhibitors in lung adenocarcinoma cells. (A) Relative nestin mRNA expression levels in the groups that were treated with $200 \mathrm{nM}$ of Akt inhibitor IV, p38 MAP kinase inhibitor (SB203580), and MEK 1/2 inhibitor (U0126). " $\mathrm{p}<0.05$ vs. untreated and DMSO-treated control cells. (B) Inhibitory effects of Akt inhibitor IV, p38 MAP kinase inhibitor (SB203580), and MEK 1/2 inhibitor (U0126) on nestin expression were determined by immunofluorescent staining, respectively. (a) DMSO-treated H1975; (b) Akt inhibitor IV-treated H1975; (c) SB203580-treated H1975; (d) U0126-treated H1975; (e) DMSO-treated PC-3; (f) Akt inhibitor IV-treated PC-3; (g) SB203580-treated PC-3; and (h) U0126-treated PC-3. Green, nestin; blue, DAPI. Scale bar, $50 \mu \mathrm{m}$. (C) Nestin expression vector-transfected PC-Nes cells were treated with $200 \mathrm{nM}$ of Akt inhibitor IV, SB203580 and U0126. Empty vector (EV)-transfected cells were used as a control. ${ }^{*}$ p $<0.05$ vs. EV-PC-Nes ${ }^{-}$and $\mathrm{EV}^{+} \mathrm{PC}-\mathrm{Nes}^{-}$cells without any treatment; ${ }^{\circledR} \mathrm{p}<0.05$ vs. EV PC-Nes ${ }^{+}$cells with or without DMSO. (D) PC-Nes cells exhibited significantly increased number of spheres, compared to untreated and EV cells. " $p<0.05$. Treatment of PC-Nes cells with inhibitors significantly decreased sphere formation. ${ }^{8} \mathrm{p}<0.05$ vs. EV-PC-Nes ${ }^{+}$cells with DMSO. Akt inhibitor IV most effectively suppressed sphere formation of PC-Nes cells compared with SB203580 and U0126 ( $\mathrm{p}<0.05$ vs. EVPC-Nes ${ }^{+}$cells with SB203580 or U0126). The inhibitory effect of Akt inhibitor IV on sphere formation was strong enough that it reduced sphere formation of PC-Nes cells to below that of untreated and $\mathrm{EV}^{+}$cells ( $<0.05$ vs. EV-PC-NES and EV+PC-Nes cells with DMSO). (E) Phase contrast images of spheres. Akt inhibitor IV strongly reduced sphere formation of PC-Nes cells. (a) EV-PC-NES- cells with DMSO; (b) EV+PC-NES cells with DMSO; (c) EV-PC-NES ${ }^{+}$with DMSO; (d) EV-PC-NES ${ }^{+}$with Akt inhibitor IV; (f) EV-PC-NES ${ }^{+}$with SB203580; and (g) EV-PC-NES ${ }^{+}$with U0126. Scale bar for upper panels, $100 \mu \mathrm{m}$.

formation. Correspondingly, nestin upregulation increased proliferation, migration, and sphere formation. Akt inhibitor IV effectively decreased the expression of nestin mRNA and protein via Sox 2 downregulation, and decreased proliferation, migration, invasion and sphere formation in AD. The effects of Akt inhibitor IV were strong enough to overcome the enhanced sphere formation induced by nestin upregulation. In conclusion, nestin regulates proliferation, migration, invasion and stemness of lung $\mathrm{AD}$, and thus nestin is considered a promising novel molecular target in $\mathrm{AD}$. 


\section{Acknowledgements}

For kindly providing the SCADS Inhibitor Kit III, we deeply thank the Screening Committee of Anticancer Drugs, which is supported by a Grant-in-Aid for Scientific Research on Innovative Areas, Scientific Support Programs for Cancer Research, from The Ministry of Education, Culture, Sports, Science and Technology, Japan. We also express our appreciation to Ms. Taeko Suzuki, Ms. Yoko Kawamoto, and Ms. Kiyoko Kawahara for technical assistance (Departments of Pathology and Integrative Oncological Pathology). We thank Dr Shin-ichi Tsuchiya (Division of Diagnostic Pathology, Nippon Medical School Hospital), Dr Yuki Nakajima, Dr Kiyoshi Koizumi, and Dr Jitsuo Usuda (Department of Surgery, Division of Thoracic Surgery, Nippon Medical School) for preparing tissue samples. This study was supported in part by Grants-in-Aid from the Japan Society for the Promotion of Science to Y.M. and T.I. (C, nos. 25462127 and 25461027), and Clinical Rebiopsy Bank Project for Comprehensive Cancer Therapy Development to Z.N., S.M. and G.A.

\section{References}

1. Ferlay J, Shin HR, Bray F, Forman D, Mathers C and Parkin DM: Estimates of worldwide burden of cancer in 2008 : GLOBOCAN 2008. Int J Cancer 127: 2893-2917, 2010.

2. Husain AN: Lung tumors. In: Robbins Basic Pathology. Kumar V, Abbas AK and Aster JC (eds.) Elsevier Saunders, Philadelphia, PA, pp505-510, 2013.

3. Non-small Cell Lung Cancer Collaborative Group: Chemotherapy in non-small cell lung cancer: a meta-analysis using updated data on individual patients from 52 randomised clinical trials. BMJ 311: 899-909, 1995.

4. Maemondo M, Inoue A, Kobayashi K, et al: Gefitinib or chemotherapy for non-small-cell lung cancer with mutated EGFR N Engl J Med 362: 2380-2388, 2010.

5. Devesa SS, Bray F, Vizcaino AP and Parkin DM: International lung cancer trends by histologic type: male:female differences diminishing and adenocarcinoma rates rising. Int $\mathrm{J}$ Cancer 117: 294-299, 2005.

6. Mitsudomi T, Morita S, Yatabe Y, et al: Gefitinib versus cisplatin plus docetaxel in patients with non-small-cell lung cancer harbouring mutations of the epidermal growth factor receptor (WJTOG3405): an open label, randomised phase 3 trial. Lancet Oncol 11: 121-128, 2010.

7. Shaw AT, Kim DW, Nakagawa K, et al: Crizotinib versus chemotherapy in advanced ALK-positive lung cancer. N Engl J Med 368: 2385-2394, 2013.

8. Choi YL, Soda M, Yamashita Y, et al: EML4-ALK mutations in lung cancer that confer resistance to ALK inhibitors. N Engl J Med 363: 1734-1739, 2010

9. Kobayashi S, Boggon TJ, Dayaram T, et al: EGFR mutation and resistance of non-small-cell lung cancer to gefitinib. N Engl J Med 352: 786-792, 2005.

10. Engelman JA, Zejnullahu K, Mitsudomi T, et al: MET amplification leads to gefitinib resistance in lung cancer by activating ERBB3 signaling. Science 316: 1039-1043, 2007.

11. Marvin MJ, Dahlstrand J, Lendahl U and McKay RD: A rod end deletion in the intermediate filament protein nestin alters its subcellular localization in neuroepithelial cells of transgenic mice. J Cell Sci 111: 1951-1961, 1998.

12. Sjöberg G, Jiang WQ, Ringertz NR, Lendahl U and Sejersen T: Colocalization of nestin and vimentin/desmin in skeletal muscle cells demonstrated by three-dimensional fluorescence digital imaging microscopy. Exp Cell Res 214: 447-458, 1994.

13. Lendahl U, Zimmerman LB and McKay RD: CNS stem cells express a new class of intermediate filament protein. Cell 60: 585-595, 1990

14. Esni F, Stoffers DA, Takeuchi T and Leach SD: Origin of exocrine pancreatic cells from nestin-positive precursors in developing mouse pancreas. Mech Dev 121: 15-25, 2004.
15. Ishiwata T, Teduka K, Yamamoto T, Kawahara K, Matsuda Y and Naito Z: Neuroepithelial stem cell marker nestin regulates the migration, invasion and growth of human gliomas. Oncol Rep 26: 91-99, 2011.

16. Akiyama M, Matsuda $\mathrm{Y}$, Ishiwata $\mathrm{T}$, Naito $\mathrm{Z}$ and Kawana $\mathrm{S}$ : Inhibition of the stem cell marker nestin reduces tumor growth and invasion of malignant melanoma. J Invest Dermatol 133: 1384-1387, 2013.

17. Kawamoto $\mathrm{M}$, Ishiwata $\mathrm{T}$, Cho $\mathrm{K}$, et al: Nestin expression correlates with nerve and retroperitoneal tissue invasion in pancreatic cancer. Hum Pathol 40: 189-198, 2009.

18. Matsuda Y, Naito Z, Kawahara K, Nakazawa N, Korc M and Ishiwata T: Nestin is a novel target for suppressing pancreatic cancer cell migration, invasion and metastasis. Cancer Biol Ther 11: 512-523, 2011.

19. Kleeberger W, Bova GS, Nielsen ME, et al: Roles for the stem cell associated intermediate filament Nestin in prostate cancer migration and metastasis. Cancer Res 67: 9199-9206, 2007.

20. Ishiwata T, Matsuda $Y$ and Naito Z: Nestin in gastrointestinal and other cancers: effects on cells and tumor angiogenesis. World J Gastroenterol 17: 409-418, 2011.

21. Ryuge S, Sato Y, Wang GQ, et al: Prognostic significance of nestin expression in resected non-small cell lung cancer. Chest 139: 862-869, 2011.

22. Ryuge S, Sato Y, Jiang SX, et al: Prognostic impact of nestin expression in resected large cell neuroendocrine carcinoma of the lung. Lung Cancer 77: 415-420, 2012.

23. Skarda J, Kolar Z, Janikova M, et al: Analysis of the prognostic impact of nestin expression in non-small cell lung cancer. Biomed Pap Med Fac, Univ Palacky Olomouc, Czech Repub 156: 135-142, 2012.

24. Chen Z, Wang T, Luo H, et al: Expression of nestin in lymph node metastasis and lymphangiogenesis in non-small cell lung cancer patients. Hum Pathol 41: 737-744, 2010.

25. Janikova M, Skarda J, Dziechciarkova M, et al: Identification

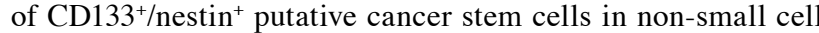
lung cancer. Biomed Pap Med Fac Univ Palacky Olomouc Czech Repub 154: 321-326, 2010.

26. Takakuwa O, Maeno K, Kunii E, et al: Involvement of intermediate filament nestin in cell growth of small-cell lung cancer. Lung Cancer 81: 174-179, 2013.

27. Goldstraw P, Crowley J, Chansky K, et al: The IASLC Lung Cancer Staging Project: proposals for the revision of the TNM stage groupings in the forthcoming (seventh) edition of the TNM Classification of malignant tumours. J Thorac Oncol 2: 706-714, 2007.

28. Ishiwata T, Matsuda Y, Yamamoto T, Uchida E, Korc M and Naito Z: Enhanced expression of fibroblast growth factor receptor 2 IIIc promotes human pancreatic cancer cell proliferation. Am J Pathol 180: 1928-1941, 2012

29. Matsuda Y, Ishiwata T, Yamahatsu K, et al: Overexpressed fibroblast growth factor receptor 2 in the invasive front of colorectal cancer: a potential therapeutic target in colorectal cancer. Cancer Lett 309: 209-219, 2011.

30. Yamahatsu K, Matsuda Y, Ishiwata T, Uchida E and Naito Z: Nestin as a novel therapeutic target for pancreatic cancer via tumor angiogenesis. Int J Oncol 40: 1345-1357, 2012.

31. Matsuda Y, Hagio M, Seya T and Ishiwata T: Fibroblast growth factor receptor 2 IIIc as a therapeutic target for colorectal cancer cells. Mol Cancer Ther 11: 2010-2020, 2012.

32. Kawase R, Ishiwata T, Matsuda Y, et al: Expression of fibroblast growth factor receptor 2 IIIc in human uterine cervical intraepithelial neoplasia and cervical cancer. Int J Oncol 36: 331-340, 2010.

33. Arai K, Sakamoto R, Kubota D and Kondo T: Proteomic approach toward molecular backgrounds of drug resistance of osteosarcoma cells in spheroid culture system. Proteomics 13: 2351-2360, 2013.

34. Ushijima $\mathrm{H}$ and Maeda M: cAMP-dependent proteolysis of GATA-6 is linked to JNK-signaling pathway. Biochem Biophys Res Commun 423: 679-683, 2012.

35. Huang YL, Wu CM, Shi GY, et al: Nestin serves as a prosurvival determinant that is linked to the cytoprotective effect of epidermal growth factor in rat vascular smooth muscle cells. J Biochem 146: 307-315, 2009.

36. Xue XJ and Yuan XB: Nestin is essential for mitogen-stimulated proliferation of neural progenitor cells. Mol Cell Neurosci 45: 26-36, 2010.

37. Brognard J, Clark AS, Ni Y and Dennis PA: Akt/protein kinase B is constitutively active in non-small cell lung cancer cells and promotes cellular survival and resistance to chemotherapy and radiation. Cancer Res 61: 3986-3997, 2001. 
38. Guo Y, Du J and Kwiatkowski DJ: Molecular dissection of AKT activation in lung cancer cell lines. Mol Cancer Res 11: 282-293, 2013.

39. Singh S, Trevino J, Bora-Singhal N, et al: EGFR/Src/Akt signaling modulates Sox 2 expression and self-renewal of stem-like side-population cells in non-small cell lung cancer. Mol Cancer 11: 73, 2012.

40. Tanaka S, Kamachi Y, Tanouchi A, Hamada H, Jing N and Kondoh $\mathrm{H}$ : Interplay of SOX and POU factors in regulation of the Nestin gene in neural primordial cells. Mol Cell Biol 24 8834-8846, 2004.

41. Dobashi Y, Kimura M, Matsubara H, Endo S, Inazawa J and Ooi A: Molecular alterations in AKT and its protein activation in human lung carcinomas. Hum Pathol 43: 2229-2240, 2012.

42. Liu K, Lin B, Zhao M, et al: The multiple roles for Sox 2 in stem cell maintenance and tumorigenesis. Cell Signal 25: 1264-1271, 2013.

43. Nakatsugawa M, Takahashi A, Hirohashi Y, et al: SOX2 is overexpressed in stem-like cells of human lung adenocarcinoma and augments the tumorigenicity. Lab Invest 91: 1796-1804, 2011.

44. Sholl LM, Barletta JA, Yeap BY, Chirieac LR and Hornick JL: Sox 2 protein expression is an independent poor prognostic indicator in stage I lung adenocarcinoma. Am J Surg Pathol 34 $1193-1198,2010$

45. Noro R, Gemma A, Kosaihira S, et al: Gefitinib (IRESSA) sensitive lung cancer cell lines show phosphorylation of Akt without ligand stimulation. BMC Cancer 6: 277, 2006.

46. Pao W, Miller VA, Politi KA, et al: Acquired resistance of lung adenocarcinomas to gefitinib or erlotinib is associated with a second mutation in the EGFR kinase domain. PLoS Med 2: e73, 2005.

47. Nolte SM, Venugopal C, McFarlane N, et al: A cancer stem cell model for studying brain metastases from primary lung cancer. J Natl Cancer Inst 105: 551-562, 2013.

48. Clarke MF, Dick JE, Dirks PB, et al: Cancer stem cells - perspectives on current status and future directions: AACR Workshop on cancer stem cells. Cancer Res 66: 9339-9344, 2006.
49. Eramo A, Lotti F, Sette G, et al: Identification and expansion of the tumorigenic lung cancer stem cell population. Cell Death Differ 15: 504-514, 2008

50. Reya T, Morrison SJ, Clarke MF and Weissman IL: Stem cells, cancer, and cancer stem cells. Nature 414: 105-111, 2001.

51. Ho MM, Ng AV, Lam S and Hung JY: Side population in human lung cancer cell lines and tumors is enriched with stem-like cancer cells. Cancer Res 67: 4827-4833, 2007.

52. Liang D and Shi Y: Aldehyde dehydrogenase-1 is a specific marker for stem cells in human lung adenocarcinoma. Med Oncol 29: 633-639, 2012.

53. Alamgeer M, Peacock CD, Matsui W, Ganju V and Watkins DN: Cancer stem cells in lung cancer: Evidence and controversies. Respirology 18: 757-764, 2013

54. Bombí JA, Martínez A, Ramírez J, et al: Ultrastructural and molecular heterogeneity in non-small cell lung carcinomas: study of 110 cases and review of the literature. Ultrastruct Pathol 26: 211-218, 2002.

55. Kau TR, Schroeder F, Ramaswamy S, et al: A chemical genetic screen identifies inhibitors of regulated nuclear export of a Forkhead transcription factor in PTEN-deficient tumor cells. Cancer Cell 4: 463-476, 2003.

56. Lam EW, Francis RE and Petkovic M: FOXO transcription factors: key regulators of cell fate. Biochem Soc Trans 34: 722-726, 2006

57. Sangodkar J, Dhawan NS, Melville H, et al: Targeting the FOXO1/KLF6 axis regulates EGFR signaling and treatment response. J Clin Invest 122: 2637-2651, 2012.

58. Zhang X, Yalcin S, Lee DF, et al: FOXO1 is an essential regulator of pluripotency in human embryonic stem cells. Nat Cell Biol 13: 1092-1099, 2011.

59. DeFeo-Jones D, Barnett SF, Fu S, et al: Tumor cell sensitization to apoptotic stimuli by selective inhibition of specific Akt/PKB family members. Mol Cancer Ther 4: 271-279, 2005. 